laboratory study suggests therefore, that further experimental and clinical evaluation of hypnotics in common use, whether barbiturates or not, is urgently required.

We are grateful to our subjects; to Roche (Products) Limited, who kindly provided, through Dr. M. Duffus, the placebo and active treatments as well as generous financial support to one of us (A.M.); and to Miss S. Virdian and D. Navsa for help with the E.E.G. recordings.

\section{REFERENCES}

Cochran, W. G., and Cox, G. M. (1957). Experimental Designs. London, Chapman and Hall.

Crossman, E. R. F. W. (1953). Quarterly fournal of Experimental Psychology, 5, 41

Davies, C., and Levine, S. (1967). British Fournal of Psychiatry, 113, 1005 .
Ditt, J. (1964). Congress of the German Society of Forensic and Social Medicine, Zurich, 17 October.

Doenicke, A., Kugler, J., Schellenberger, A., and Gürtner, T. (1966). British fournal of Anaesthesia, 38, 580 .

Goodnow, R. E., Beecher, H. K., Brazier, M. A. B., Mosteller, F., and Tagiuri, R. (1951). fournal of Pharmacology and Experimental Therapeutics, 102, 55

Haider, I. (1968). British fournal of Psychiatry, 114, 337.

Harrer, G. (1965). Progress in Brain Research, 18, 228.

Kornetsky, C., Vates, T. S., and Kessler, E. K. (1959). Fournal of Pharmacology and Experimental Therapeutics, 127, 51 .

Malpas, A., and Joyce, C. R. B. (1969). Psychopharmacologia, 14, 167.

Matthew, H., Proudfoot, A. T., Aitken, R. C. B., Raeburn, J. A., and Wright, N. (1969). British Medical fournal, 3, 23

Morgan, H., Scott, D. F., and Joyce, C. R. B. (1970). British fournal of Psychiatry. In press.

Oswald, I., and Priest, R. G. (1965). British Medical fournal, 2, 1093.

Prior, P. F., and Deacon, P. A. (1969). Electroencephalography and Clinical Neurophysiology, 27, 422.

Reynolds, E., Joyce, C. R. B., Swift, J. I., Tooley, P. H., and Weatherall, M. (1965). British fournal of Psychiatry, 111, 84.

Volavka, J. V., et al. (1969). Psychopharmacologia 14, 178 .

Wyss, S. and Mäder, A (1965) Schweizerische medizinische Wochenschrift, 95, 338

\title{
Long-term and Short-term Effects of Oral Prethcamide in Chronic Ventilatory Failure
}

\author{
R. A. L. BREWIS, ${ }^{*}$ M.D., ; M.R.C.P. N. G. HODGES, $\dagger$ M.B., B.CH., M.R.C.P.
}

Sum ummary: The effect of oral prethcamide (Micoren) (a mixture of two related amides of crotonyl $\mathbf{N}^{\prime}$ butyric acid) was compared with a placebo preparation in 13 patients with established chronic ventilatory failure. Part I of the study comprised a double-blind single crossover trial with an initial assessment and two further assessments at the end of each period of one month. Prethcamide was taken in 200-mg. doses four times daily. No subjective or objective changes were noted, and in particular the resting $\mathrm{PCO}_{2}$ showed no change.

Part II of the study comprised a double-blind single cross-over trial of the short-term effect of prethcamide compared with placebo in 12 patients in chronic ventilatory failure. Frequent estimations of mixed venous PCO: were made with a rebreathing technique for four and a half hours after ingestion of prethcamide or placebo preparation.

Following prethcamide a fall in PCO.2 level to a minimum value at 30 minutes of $93 \%$ of control values and persisting for about three hours was noted for the group as a whole. The fall represents a lowering by about $4 \mathrm{~mm}$. $\mathrm{Hg}$ of the mixed venous $\mathrm{PCO}_{2}$.

It is concluded that, though in patients with chronic ventilatory failure prethcamide may reduce the PCO: in the short term, there is no subjective benefit or observable objective change following repeated administrations over a period of one month.

\section{Introduction}

Patients with obstructive airways disease who develop chronic ventilatory failure commonly have a less severe degree of air-

* Lecturer in Medicine, University of Manchester. At present Senio Lecturer in Medicine, Royal Victoria Infirmary, Newcastle upon Tyne NE1 4LP.

+ Research Fellow, United Manchester Hospitals. At present Registrar in Medicine, Southampton General Hospital, Southampton. ways obstruction than some other patients who are, nevertheless able to maintain a normal arterial $\mathrm{PcO}_{2}$. While there may be differences of lung morphology in these two groups, there is strong evidence that some patients with chronic hypoventilation have a defective central drive to breathe, and voluntary overbreathing in these individuals results in a lowering of the arterial $\mathrm{PCO}_{2}$ and an increase in $\mathrm{Po}_{2}$. In these patients stimulation of ventilation might prove beneficial. Respiratory stimulants such as nikethamide have found some place in the management of acute respiratory failure accompanying acute exacerbations of chronic obstructive airways disease (Lancet, 1963). Prethcamide (Micoren), a mixture of two related amides of crotonyl $\mathrm{N}^{\prime}$ butyric acid, has been shown to stimulate respiration in the short term (Domenet and Kennedy, 1967) and has been used in the acute situation, but no controlled trial of the long-term use of this drug, orally, in patients with established chronic ventilatory failure has been reported to date.

\section{Patients and Methods}

\section{Part I. Long Term}

Sixteen patients with chronic ventilatory failure attending the respiratory clinic at Manchester Royal Infirmary were admitted to the trial. In every case the three previous estimations of the arterial $\mathrm{PCO}:$ were in excess of $44 \mathrm{~mm}$. $\mathrm{Hg}$ and extended over a period of at least three months before the beginning of the trial. The study took the form of a doubleblind comparison of prethcamide and placebo, each administered for four weeks. All patients had an initial assessment, and a further assessment at the end of each period. Prethcamide was prescribed in the form of capsules, each containing $200 \mathrm{mg}$., and a dose of $400 \mathrm{mg}$. was taken four times daily. The patients were provided with typewritten information about the trial and specifically urged to continue taking the capsules up to and including the morning of the next assessment. The placebo preparation was identical in appearance. 
The study took place over the spring of 1969 , and to guard against any possible effect of seasonal improvement patients were admitted in groups of four in which two had placebo in the first period and two the active preparation, the allocation being otherwise random.

At each assessment the patient was asked to score breathlessness, exercise tolerance, and cough, by making, for each, a mark on a $10-\mathrm{cm}$. line marked "perfect" at one end and "terrible" at the other. The distance in $\mathrm{mm}$. from the mark to the "terrible" end of the line was subsequently measured. The patient was asked whether the preceding month had been better, the same, or worse than the month before that. Work loss, exacerbations, changes in therapy, and side-effects were also noted. The time at which the morning dose had been taken was also recorded. The arterial $\mathrm{PCO}_{2}$ was estimated from the mixed venous $\mathrm{PCO}_{2}$ by the rebreathing technique of Campbell and Howell (1962). The $\mathrm{PCO}_{2}$ was measured after resting seated for 15 minutes and again after a further 15 minutes. If the two results differed by more than $2 \mathrm{~mm}$. $\mathrm{Hg}$ a third reading was taken after a further 15 minutes. Duplicate analyses were performed on each bag and a mean of all the readings taken was recorded. For convenience this mixed venous PCO: was converted to an "arterial" PCO. by subtracting $9 \mathrm{~mm}$. Hg. A reproducible forced expiratory spirogram was obtained with a Vitalograph, and F.E.V.1 and forced vital capacity were measured.

Analysis of Results.-The difference between the results at control, placebo, and prethcamide assessments were calculated, and for each assessment the mean and standard deviation was calculated for the group as a whole for each of the three assessments. For each patient the differences between the values obtained at each assessment were calculated and the differences between the prethcamide, placebo, and control assessments subjected to Student's $t$ test.

\section{Part II. Short Term}

Eleven of the 13 patients who completed part I of the trial and one who did not complete it took part in a double-blind controlled trial designed to assess the immediate effects of a single oral dose of prethcamide. None had received the drug for at least three weeks previously. On two mornings, two days apart, the patients, after a light breakfast, attended the respiratory department. After they had rested for 10 minutes three estimations of the arterial $\mathrm{PCO}_{2}$ by the rebreathing technique were made at 15 -minute intervals. A dose of $400 \mathrm{mg}$. of prethcamide or an identical placebo preparation was then administered orally. Pco: estimations continued at 15-minute intervals for one hour and then at half-hourly intervals until two and a half hours after the dose, when a light sandwich lunch was taken. After a 15-minute interval estimations continued at half-hourly intervals until four and a quarter hours from the time of taking the dose. The $\mathrm{CO}_{2}$ concentration of the rebreathing bags was measured from the recorded tracing from a Grubb Parsons $\mathrm{CO}_{2}$ analyser frequently calibrated with three standard $\mathrm{CO}_{2} / \mathrm{O}_{2}$ mixtures spanning the range used. An "arterial" PCO: was derived from the mixed venous $\mathrm{PCO}_{2}$ as in part I of the trial.

Analysis of Results.-The mean of the three control $\mathrm{Pco}_{2}$ values was calculated. Subsequent $\mathrm{PCO}_{2}$ estimations were expressed as a percentage of this value. The results for the group as a whole were expressed by calculating the mean value and standard error for each period after the dose for each of the two days. Individual responses were assessed by subtracting active from placebo mean percentage drugs from control values for each period after the dose. The significance of the variation of these differences from zero was then assessed with Student's $t$ test.

\section{Results}

\section{Part I. Long Term}

Of 16 patients admitted to the trial three were subsequently withdrawn. One was admitted to hospital and died in acute respiratory failure soon after the trial was begun. One patient developed gastrointestinal symptoms on both active and placebo preparations and was taking neither at the time of the assessments. The third patient tolerated the placebo prepara:ien and showed no subjective or objective change but developed increased breathlessness after each dose of the active preparation and ceased taking it. The results reported refer to the remaining 13 patients and are summarized in Tables I and II.

TABLE I.-Derived "Arterial" $\mathrm{PcO}_{2}(\mathrm{~mm} . \mathrm{Hg})$ at the Three Assessments of Part I of the Trial (Long Term)

\begin{tabular}{|c|c|c|c|c|c|c|}
\hline \multicolumn{4}{|c|}{ Case No. } & \multirow[b]{2}{*}{$\begin{array}{l}\text { Control } \\
57 \\
57 \cdot 5 \\
55 \\
63 \cdot 5 \\
51 \\
59 \\
58 \\
48 \\
53 \\
51 \\
53 \\
52 \\
52.5\end{array}$} & \multirow[b]{2}{*}{$\begin{array}{l}\text { Placebo } \\
55 \cdot 5 \\
60 \cdot 5 \\
60 \cdot 5 \\
69 \\
48 \\
68 \cdot 5 \\
77 \\
43 \\
51 \\
48 \\
47 \cdot 5 \\
51 \cdot 5 \\
66.5\end{array}$} & \multirow[b]{2}{*}{$\begin{array}{l}\text { Prethcamide } \\
52 \cdot 5 \\
68 \\
62 \\
59 \cdot 5 \\
47 \cdot 5 \\
67 \cdot 5 \\
76 \\
43 \\
54 \\
49 \\
51 \\
57 \cdot 5 \\
68\end{array}$} \\
\hline $\begin{array}{r}1 \\
2 \\
3 \\
4 \\
5 \\
6 \\
7 \\
8 \\
9 \\
10 \\
11 \\
12 \\
13\end{array}$ & $\begin{array}{l}\cdots \\
\therefore \\
\cdots \\
\therefore \\
\cdots \\
\cdots \\
\cdots \\
\cdots \\
\cdots \\
\cdots\end{array}$ & $\begin{array}{l}\because \\
\because \\
\because \\
\because \\
\because \\
\because \\
\because \\
\because \\
\because \\
\therefore\end{array}$ & $\begin{array}{l}\cdots \\
\because \\
\because \\
\cdots \\
\cdots \\
\cdots \\
\cdots \\
\cdots \\
\cdots \\
\therefore\end{array}$ & & & \\
\hline $\mathrm{Mea}$ & D.) & $\ldots$ & $\ldots$ & $54 \cdot 7(4 \cdot 2)$ & $57 \cdot 4(10 \cdot 4)$ & $58 \cdot 1(9 \cdot 8)$ \\
\hline
\end{tabular}

TABLE II.-Summary of Results of Part 1 of the Trial (Long Term)

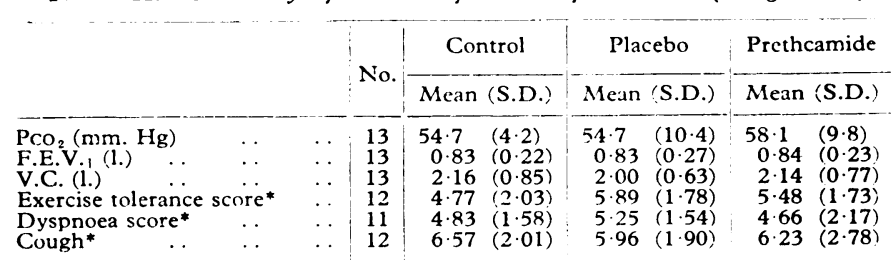
*Deri

The mean PCO: after taking prethcamide for a month was slightly higher than the mean level after the control period or at the initial assessment. Only three patients had a lower $\mathrm{PCO}_{2}$ after taking prethcamide than at the other two assessments. Analysis of the results showed that the $\mathrm{PCO}_{2}$ levels at the three assessments were not significantly different. There was no significant change in the F.E.V.1 or V.C. at the various assessments. The patients' own scores for exercise tolerance, breathlessness, and cough similarly showed no significant change. The patients' overall assessment of each month compared with the month before is shown in Table III. No preference for either prethcamide or placsbo emerged.

TABLE III-Part I of the Trial (Long Term). Patients' Own Assessment of the Month Past Compared with the Month Before That

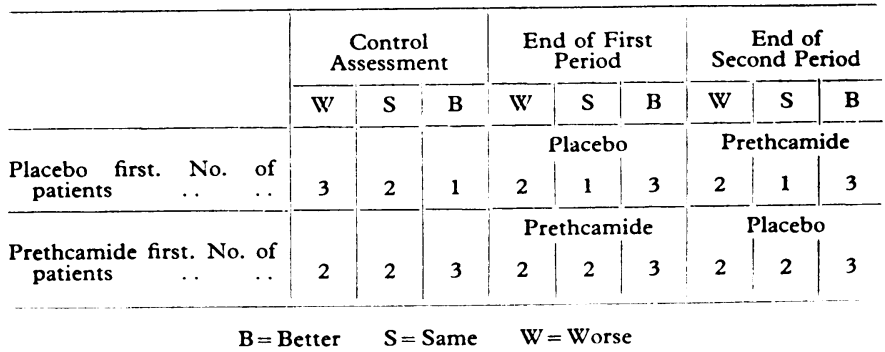




\section{Part II. Short Term}

The mean resting $\mathrm{PCO}_{2}$ for the group as a whole was 61 $\mathrm{mm}$. $\mathrm{Hg}$ and the effect of a single oral dose of prethcamide is shown in the Chart. A fall in $\mathrm{PCO}_{2}$ after prethcamide reaching

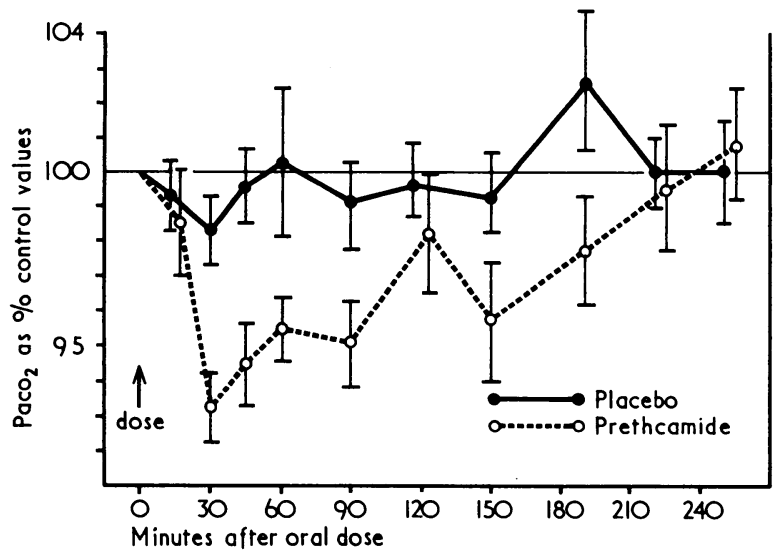

a minimum at 30 minutes and lasting for three hours is shown. Thirty minutes after the oral dose the mean $\mathrm{PCO}_{2}$ for the group as a whole was $93.3 \%$ of the control value. This represents an average fall of just over $4 \mathrm{~mm}$. $\mathrm{Hg}$. Analysis of the individual responses (Table IV) shows that 5 of the 12 TABLE IV.-Part II of the Trial (Short Term). Mean Difference over
Four and a Half Hours in Changes from Control PCO2 Values (- indicates $\mathrm{PCO}_{2}$ Less on Prethcamide)

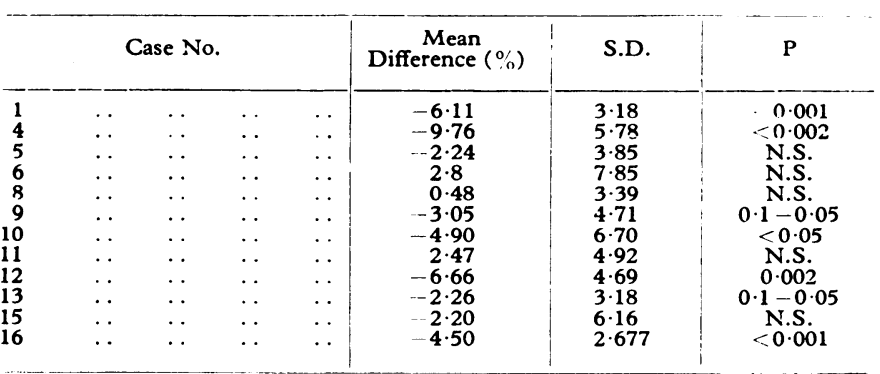

$\mathrm{PaCO}_{2}$ expressed as a percentage of the control values after a single oral dose of prethcamide $400 \mathrm{mg}$. or placebo.

patients had a significant difference between the two assessments and in all five the lower $\mathrm{PCO}_{2}$ values were obtained on prethcamide. A further four patients showed lower $\mathrm{PCO}_{2}$ levels after prethcamide than : ${ }^{\text {ier }}$ placebo, but the difference was not significant.

\section{Discussion}

The results presented reaffirm the respiratory stimulant effect of prethcamide and show that patients with chronic obstructive airways disease and chronic ventilatory failure can be induced to increase their resting alveolar ventilation slightly with an oral dose of $400 \mathrm{mg}$. It seems reasonable, to assume that neither change in cardiac output nor $\mathrm{CO}_{2}$ production is responsible for the observed lowering of $\mathrm{PCO}_{2}$. We have not been able to demonstrate any objective or subjective response to regular consumption of prethcamide. W The possible explanations for the failure to observe lowering of the $\mathrm{PCO}_{2}$ on long-term treatment are: (1) the patients failed to take the drug, (2) the effect of the morning dose had $c$ passed before they were observed, (3) tolerance to the drug developed, and (4) the variations in resting $\mathrm{PCO}_{2}$ between visits one month apart were large enough to mask the small effect of the drug.

We believe that failure to take the drug regularly is unlikely to be the explanation in this particular group of patients, $\stackrel{\AA}{\Omega}$ who were extremely co-operative (as the excellent atten- is dances for part II of the trial show). They were explicitly $\vec{O}$ asked to take the dose as usual on the morning of the assessments, and the assessments were almost all performed between one and a half and three and a half hours after the morning dose had been taken. The peak effect noted during the short-term trial occurred at 30 minutes, but a lowering was still present at three hours. We believe that failure to or find any effect after long-term administration of prethcamide $\vec{N}$ is due to the development of tolerance, to the weak effect of the drug being masked by the wide variations in $\mathrm{PCO}_{2}$, or to both those factors.

Boulet et al. (1963) noted a fall of about $10 \mathrm{~mm}$. Hg. from pretreatment arterial $\mathrm{PCO}_{2}$ levels persisting 24 hours after the completion of a 15-day open trial of a twice-daily oral dose of $375 \mathrm{mg}$. of prethcamide. The fall in $\mathrm{PCO}_{2}$ was found in every patient. Only 3 of the 12 patients studied had an arterial $\mathrm{Pco}_{2}$ level in excess of $46 \mathrm{~mm}$. $\mathrm{Hg}$. There is no obvious explanation for the discrepancy between this result and that of the present study. Our failure to find any improvement in the vital capacity or to find any subjective improvement is in contrast to the report by Germouty and Jault (1965).

On the basis of a one-month trial we find nothing to support the long-term administration of this drug to patients with obstructive airways disease and chronic ventilatory failure, and doubt whether the short-term response we have found is large enough to be clinically worth while. We would emphasize that none of the patients were studied during an acute exacerbation. Possibly the drug has some place in this context and in combating the fall in ventilation which may accompany oxygen therapy.

We are grateful to Dr. J. G. Domenet, of Geigy (U.K.) Limited, for supplies of Micoren and to Professor J. B. L. Howell for advice and permission to study patients under his care. One of us (N. G. H.) was in receipt of a research fellowship from United Manchester Hospitals.

\section{REFERENCES}

Boulet, P., Barion, P., and Fabre, S. (1963). Semaine Thérapeutique, 39,

Campbell, E. J. M., and Howell, J. B. L. (1962). British Medical four-

nal, 2, 630. Diseases of the Chest, 61, 25 .

Germouty, J., and Jault, D. (1965). Progrès Médical (Paris), 93, 357. Lancet, 1963, 2, 344 . 